\title{
Få eget domænenavn - få egen URL
}

\author{
http://www.mit-eget-tidsskriftsnavn.dk
}

\section{i stedet for}

http://ojs.statsbiblioteket.dk/index.php/mit-eget-tidsskriftsnavn.dk

Bemærk: Vi hedder ikke længere ojs.statsbibliotekt.dk/index.php men derimod tidsskrift.dk, så det er sidstnævnte, der skal indføres i diverse relevante felter. 


\section{Få eget domænenavn - få egen URL}

Her findes den korte instruktion, som efterfølgende vil blive uddybet og eksemplificeret .

For at et tidsskrift kan få sit eget domæne skal følgende foretages:

- Ejerne af tidsskriftet skal købe et domæne til formålet ${ }^{1}$

- Hos domæneudbyderen skal der oprettes et DNS CNAME, der peger på Statsbibliotekets OJS-server ${ }^{2}$

- Statsbiblioteket tilføjer konfigurationen til OJS-installationen og til webserveren på OJS-serveren 


\section{Opret domænenavn}

Oprettelse og køb af domænenavn ved GratisDNS.dk foregår fra firmaets forside. I stedet for 'eksempel' indskrives det ønskede navn, og fra dropdown-menuen vælges dk (andre endelser er dyrere end de tidligere nævnte 99 kr.), og der klikkes på knappen 'S $\varnothing$ g!'.

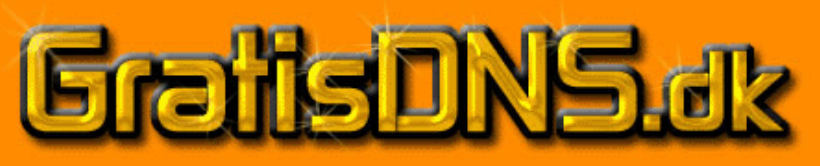

Forside Nyheder Kontrolpanel Prisliste Support Handelsbetingelser Om os

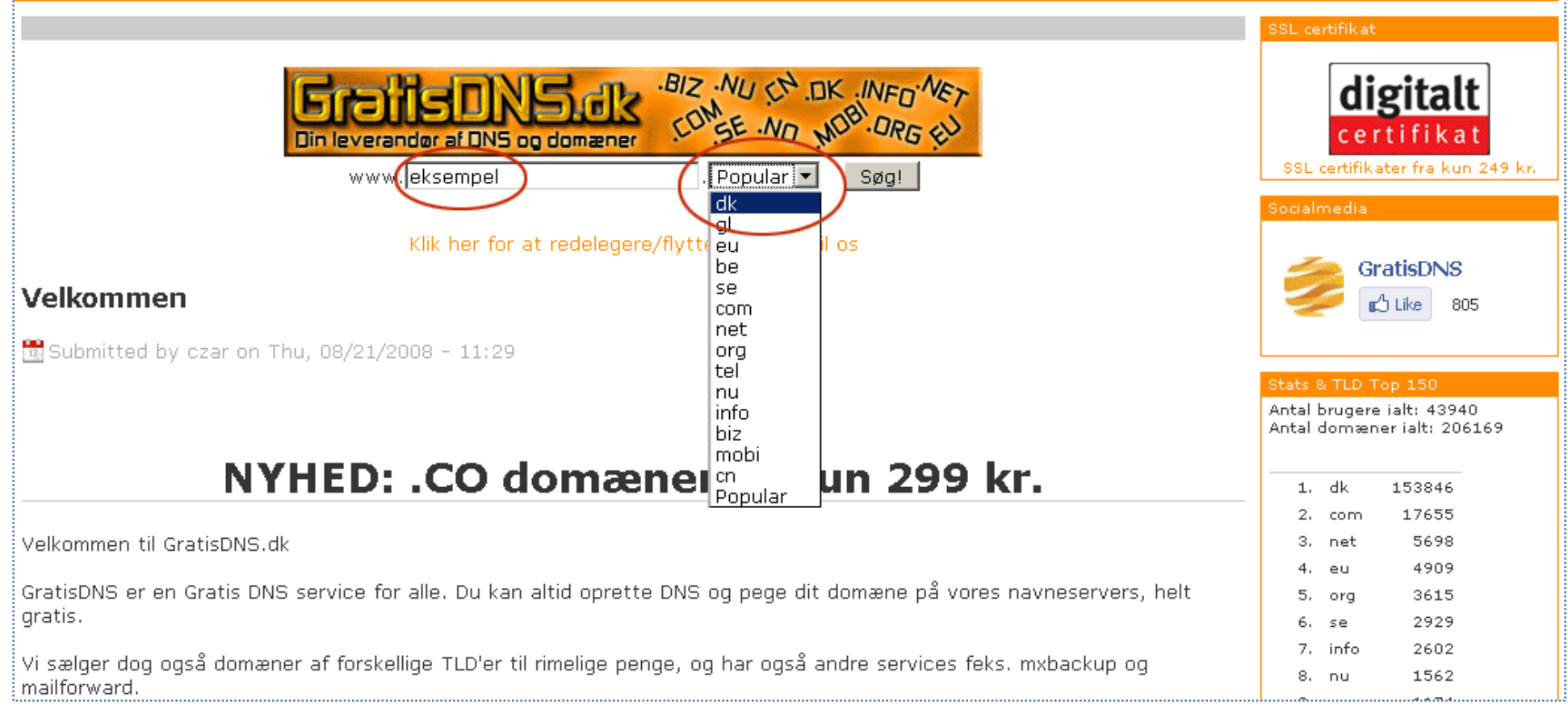


Eksempel på oprettelse af DNS CNAME via domæneudbyderen GratisDNS.dk

Efter køb af domæne skal du logge dig ind på DNS' kontrolpanel.

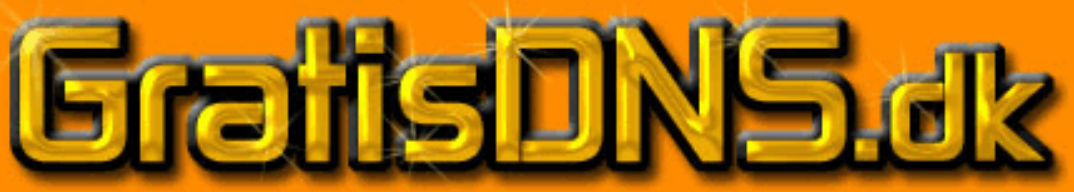

DNS kontrolpanel

Login Opret ny bruger Info Support DNS ordbog Sikkerhed

System besked:

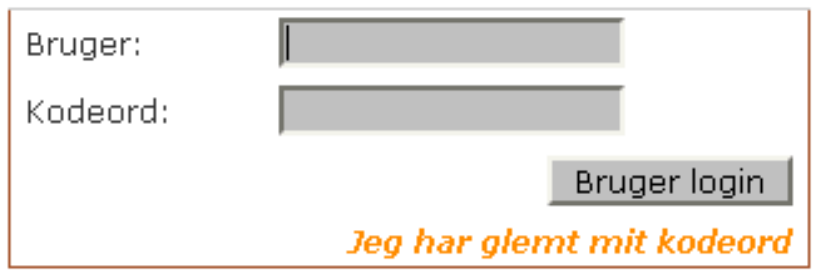

Hwis du har en OpenID konto, så kan du logge på med den her:

Click to Sign In 


\section{Eksempel på oprettelse af DNS CNAME}

\section{På den fremkomne side vælger du knappen 'Primær DNS'}

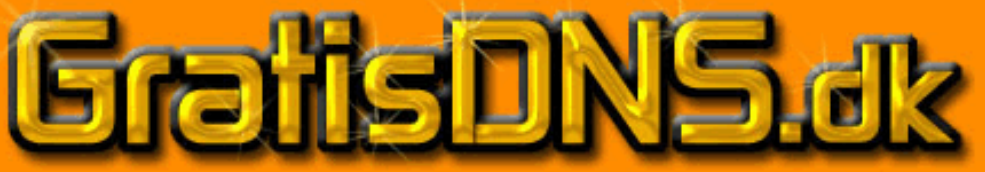

DNS kontrolpanel

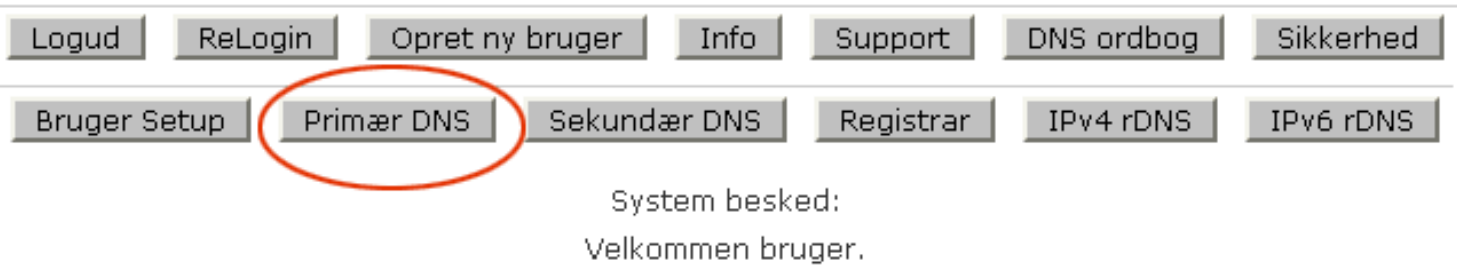

velkommen til administrations varktgjet

Er du ny, så kig dig omkring, se især DNS ordbogen, og support knapperne.

For at navigere videre, så skal du bruge anden rakke af knapper, dvs. Bruger setup, Primær DNS osv.

Husk altid at din e-mail adresse bør være sat til en e-mail adresse du læser, vi bruger den til fejlmeddeleser og andet, så det er også godt at den er UDENFOR det/de domæne(r) du bestyrer.

Har du brug for hjæelp, så brug venligst vores support forum.Du kan nu tilmelde dig nyhedsbrevet/tilbud ved at trykke på denne knap:

Tilmeld mig nyhedsbrevet og send mig tilbud når i laver kampagner på produkter 


\section{Eksempel på oprettelse af DNS CNAME}

..og her vælges knappen 'Andre DNS'

\section{Frefilis N5G.dls}

DNS kontrolpanel

Logud ReLogin Opret ny bruger Info Support DNS ordbog Sikkerhed

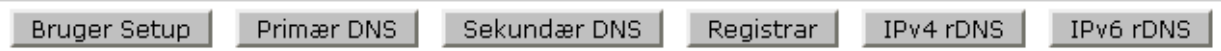

System besked:

Primær DNS domæner

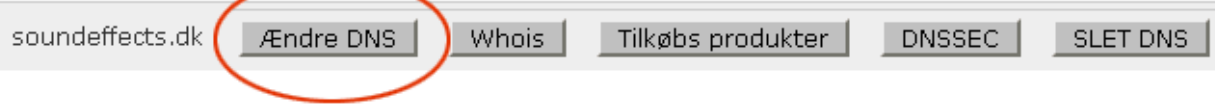

Antal domæner: 1

Nyt domæne der skal have både primær og nytprimærtdomæne.d

Opret primær \& sekundær DNS for dette domæne

Ny template til domæner der skal have både primær Navn på template

Opret primær \& sekundær DNS for denne template 


\section{Eksempel på oprettelse af DNS CNAME}

På denne side scrolles der ned til afsnittet CNAME, hvor knappen 'Tilføj CNAME' aktiveres.

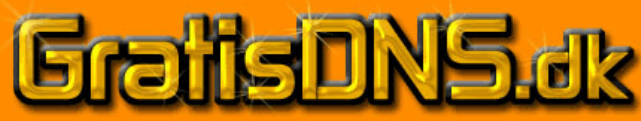

DNS kontrolpanel

Logud ReLogin Opret ny bruger Info Support DNS ordbog Sikkerhed Bruger Setup Primær DNS Sekundær DNS Registrar IPv4 rDNS IPv6rDNS

System besked:

soundeffects.dk

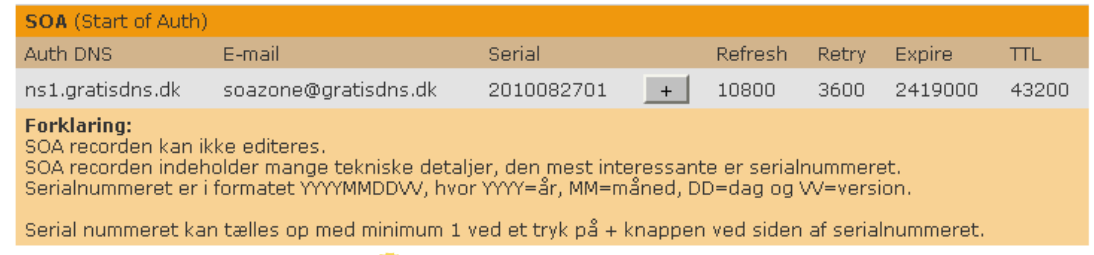

Serial nummeret kan tælles op med minimum 1 ved et tryk på + knappen ved siden af serialnummeret.

AAAA (Navn $\rightarrow$ IPv6 adresse)

Vart IPv6

Forklaring:

AAAA records angiver IPv6 adresser.

De fleste mennesGS: kan du være helt sikker på du IKKE skal bruge dette til noget!! Spring da disse informationer over!

Man kan lave de AAAA records man ønsker. Feks. "Www.domæne.dk $\rightarrow 123: 45 f: 34 a: 23 f: 34 f: 4 f f: d e: 34 e^{\prime \prime}$. Man matche feks "www.domæne.dk" og "ftp.domæne.dk", men IKKE "domæne.dk". Vælger man at bruge begge records, så vil stjernealiaset fange det som er udefineret, feks "ftp.domæne.

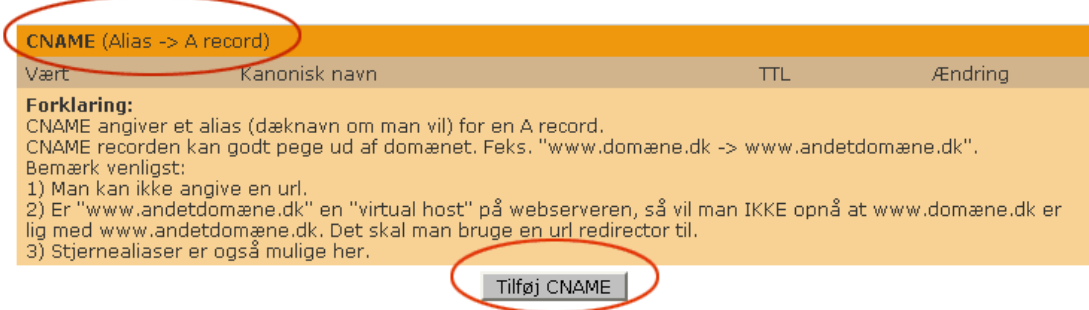

Tilføj $\triangle \triangle \triangle \Delta A$

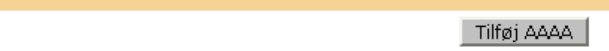




\section{Eksempel på oprettelse af DNS CNAME}

Herefter fremkommer nedenstående side, hvor jeres domænenavn vil figurere i de to viste felter (her soundeffects.dk).

Følgende tilretninger skal foretages:

- Udskift * med www i feltet 'Vært'

- I feltet 'Kanonisk navn' skrives ojs.statsbiblioteket.dk

- Der klikkes på knappen 'Tilføj CNAME recorden'

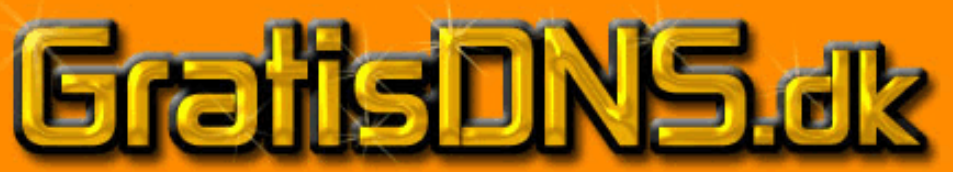

DNS kontrolpanel

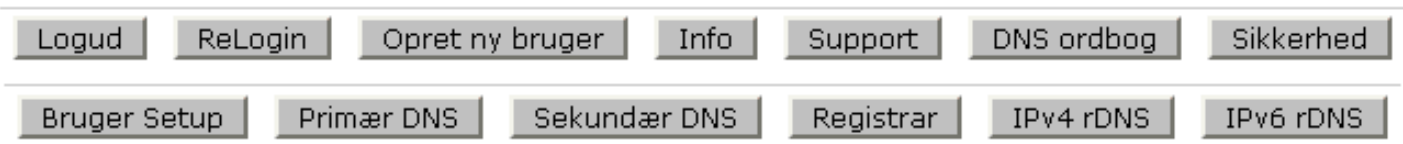

System besked:

Tilfaj CNAME

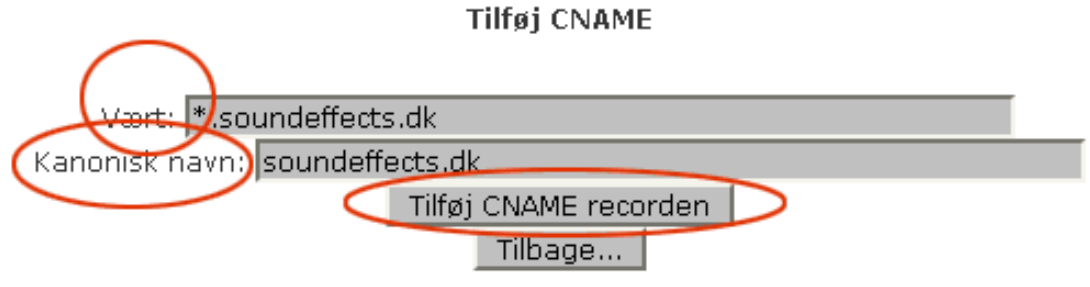




\section{Eksempel på oprettelse af DNS CNAME}

Herefter melder systemet tilbage, at handlingen er udført "successfyldt", og under afsnittet 'CNAME' er domænenavnet og ojs.statsbiblioteket.dk nu indskrevet.

Når det er sket bedes I kontakte undertegnede, der efterfølgende vil sørge for, at Statsbibliotekets OJS-server registrerer dette.

Niels Erik Frederiksen nef@statsbiblioteket.dk

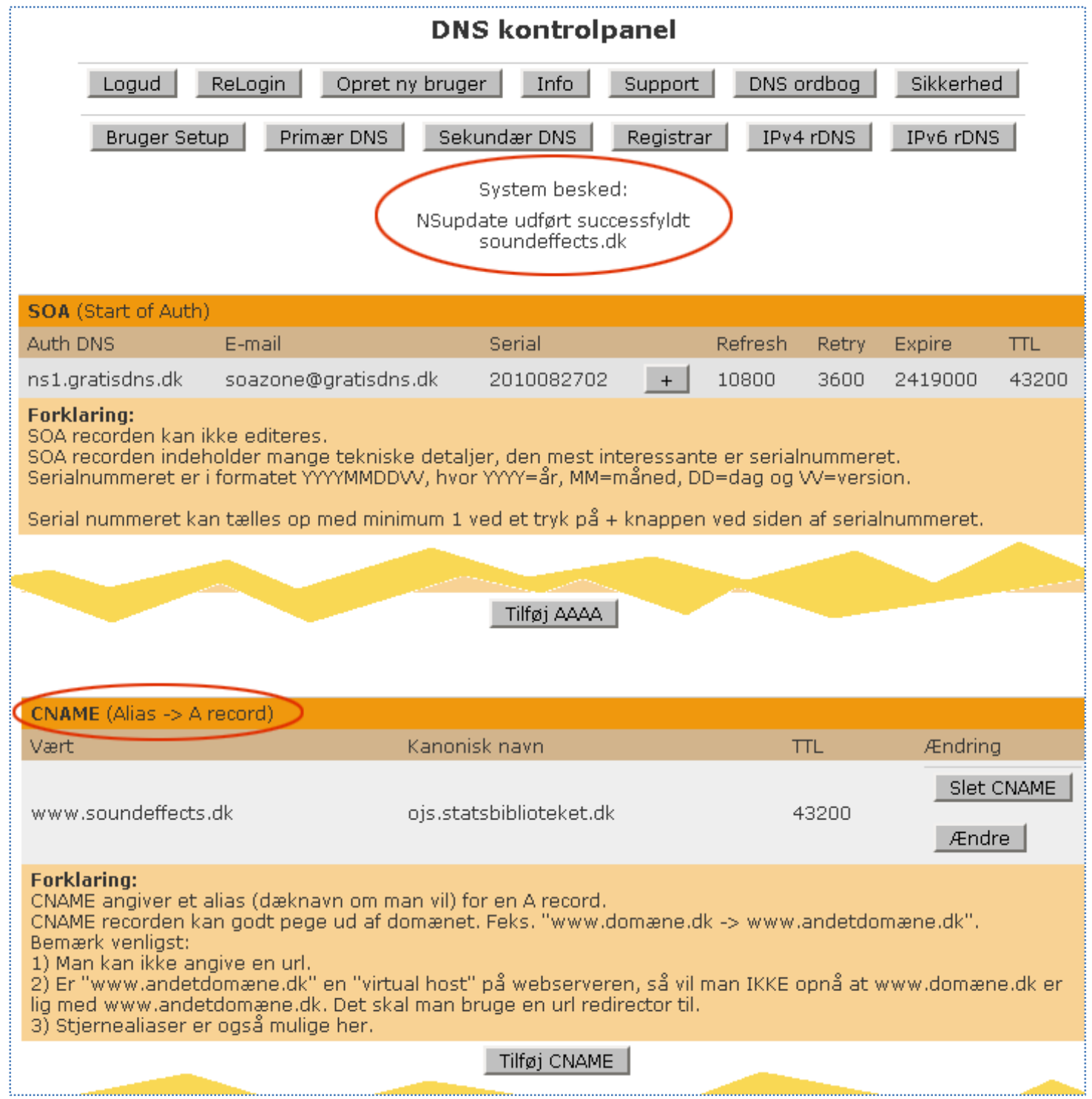

